\title{
Evaluating heterotrophic growth in a nitrifying biofilm reactor using fluorescence in situ hybridization and mathematical modeling
}

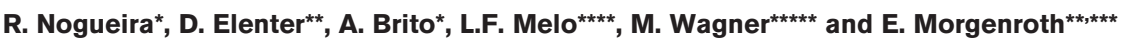 \\ ${ }^{*}$ Centro de Engenharia Biológica, Universidade do Minho, Campus de Gualtar, 4700-057 Braga, Portugal \\ (E-mail: regina@deb.uminho.pt; agbrito@deb.uminho.pt) \\ **Department of Civil and Environmental Engineering, University of Illinois at Urbana-Champaign, Urbana, \\ Illinois 61801, USA (E-mail: elenter@uiuc.edu) \\ ***Department of Animal Sciences, University of Illinois at Urbana-Champaign, Urbana, Illinois 61801, USA \\ (E-mail: emorgenr@uiuc.edu) \\ ****Departamento de Engenharia Química, Faculdade de Engenharia of Porto, 4200-465 Porto, Portugal \\ (E-mail: Imelo@fe.up.pt)

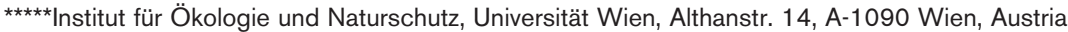 \\ (E-mail: wagner@microbial-ecology.net)
}

Abstract The objective of this study was to evaluate the significance of heterotrophic growth in nitrifying biofilm reactors fed only with ammonium as an energy source. The diversity, abundance and spatial distribution of nitrifying bacteria were studied using a combination of molecular tools and mathematical modeling, in two biofilm reactors operated with different hydraulic retention times. The composition and distribution of nitrifying consortia in biofilms were quantified by fluorescence in situ hybridization (FISH) with rRNA-targeted oligonucleotide probes combined with confocal laser scanning microscopy (CLSM) and digital image analysis. Autotrophic and heterotrophic biofilm fractions determined by FISH were compared to the output from a multispecies model that incorporates soluble microbial products (SMP) production/consumption. In reactor R1 (short retention time) nearly 100\% of the total bacteria could be identified as either ammonia- or nitrite-oxidizing bacteria by quantitative FISH analyses, while in reactor R2 (long retention time) the identification rate was only 73\%, with the rest probably consisting of heterotrophs. Mathematical simulations were performed to evaluate the influence of the hydraulic retention time (HRT), biofilm thickness, and substrate utilization associated SMP production on the growth of heterotrophic bacteria. The model predicts that low HRTs resulted in a lower availability of SMPs leading to purely autotrophic biofilms. These model predictions are consistent with experimental observations. At HRTs that are about an order of magnitude larger than the reciprocal of the net maximum growth rate the majority of the active biomass will grow suspended in the bulk phase rather than in the biofilm.

Keywords Nitrification; biofilm; fluorescence in situ hybridization; mathematical modeling

\section{Introduction}

The so-called nitrification process, that is the catalytic oxidation of ammonia to nitrite and then to nitrate, is carried out by chemolithoautotrophic ammonia and nitrite oxidizing bacteria, which are therefore summarized as nitrifying microorganisms. Nitrifying microorganisms reduce inorganic carbon to form cell mass and excrete organic carbon (soluble microbial products, SMP) into the medium that supports heterotrophic growth. Coexistence of nitrifiers and heterotrophs has been found in autotrophic nitrifying suspended cultures (Rittmann et al., 1994) and biofilms (Kindaichi et al., 2004) grown without an external organic carbon source. This feature of nitrifying microorganisms has already been considered in mathematical models used to describe the competition for oxygen and space between autotrophs and heterotrophs (Furumai and Rittmann, 1994, and Lu et al., 
2001). In this work, heterotrophic growth in a nitrifying biofilm reactor was evaluated using fluorescence in-situ hybridization (FISH) and mathematical modeling.

\section{Materials and methods}

Experimental set-up and routine analyses

Two laboratory-scale circulating bed biofilm reactors of 1.21 each, described in detail elsewhere (Nogueira et al., 2002), were employed for this study. The operating conditions are presented in Table 1 . The temperature was maintained at $30^{\circ} \mathrm{C}$ and the $\mathrm{pH}$ was controlled at 7.5 with $\mathrm{NaOH}(1 \mathrm{M})$. High density polyethylene granulate with a particle size of $1 \mathrm{~mm}$ and a density of $731 \mathrm{~kg} / \mathrm{m}^{3}$ was used as support material for biofilm growth. Ammonium, nitrite and nitrate ions were determined photometrically (LCK, Dr. Lange). Biofilm mass was measured gravimetrically according to APHA (1995).

\section{FISH and confocal laser scanning microscopy}

In situ hybridization of cells in the biofilm was performed with fluorescently labeled rRNA-targeted oligonucleotide probes according to the method of Manz et al. (1992). First the samples were hybridized with a EUB338 probe set (EUB338, EUB338-II, EUB338-III) designed to target almost all bacteria (Daims et al., 2001). Then, within this domain, the beta and gamma-subclasses of Proteobacteria were labeled with the respective group specific probes Bet42a and Gam42a (Manz et al., 1992). Within the beta-subclasses, in turn, the ammonia-oxidizing bacteria (AOB) were detected using the following probes: (i) Nso1225 and Nso190, which are specific for all ammonia-oxidizers in the beta subclass Proteobacteria (Mobarry et al., 1996); (ii) Neu, which is specific for halophilic and halotolerant Nitrosomonas spp. and Nitrosococcus mobilis (Wagner et al., 1995); and (iii) $\mathrm{NmV}$, specific for the Nitrosococcus mobilis lineage (Juretschko et al., 1998). The following probes were used to detect nitrite-oxidizing bacteria (NOB): (i) Nit3, which is complementary to a sequence region of all Nitrobacter species (Wagner et al., 1996); (ii) Ntspa712, specific for most members of the phylum Nitrospira (Daims et al., 2001); and (iii) Ntspa662, specific for the genus Nitrospira (Daims et al., 2001). For quantification of the different probe-targeted bacteria, simultaneous hybridizations were performed with Cy3 labeled specific probes and the Cy5 labeled bacterial probe set. For each confocal image, the relative cellular area was determined, defined as the ratio of the area of those cells labeled by the specific probe versus the area of all bacteria stained by the EUB338 probe set. Fluorescence signals were recorded with an LSM 510 confocal laser scanning microscope (Zeiss, Germany) equipped with two HeNe lasers (543 nm and $633 \mathrm{~nm}$ ) for detection of $\mathrm{Cy} 3$ or $\mathrm{Cy} 5$.

Table 1 Operating conditions and performance of reactors R1 and R2 at steady-state*

\begin{tabular}{|c|c|c|c|}
\hline$\downarrow$ Parameters & Reactors $\rightarrow$ & $\mathbf{R} 1$ & $\mathbf{R 2}$ \\
\hline Hydraulic retention time $^{\dagger}, H R T(\mathrm{~d})$ & & 0.0175 & 0.13125 \\
\hline Influent $\mathrm{C}_{\mathrm{N}-\mathrm{NH} 4+}(\mathrm{mg} / \mathrm{l})$ & & 39 & 250 \\
\hline Effluent $\mathrm{C}_{\mathrm{N}-\mathrm{NH} 4+}(\mathrm{mg} / \mathrm{l})$ & & 1.8 & 0.4 \\
\hline Effluent $\mathrm{C}_{\mathrm{N}-\mathrm{NO} 2-}(\mathrm{mg} / \mathrm{l})$ & & 1.9 & 0.6 \\
\hline Effluent $\mathrm{C}_{\mathrm{N}-\mathrm{NO}}-(\mathrm{mg} / \mathrm{l})$ & & 35 & 249 \\
\hline Biofilm mass $C_{\mathrm{BF}}(\mathrm{mg} / \mathrm{l})$ & & 2.7 & 2.7 \\
\hline Suspended biomass $C_{\text {bulk }}($ cell/ml) & & $1.3 \times 10^{6}$ & $5 \times 10^{6}$ \\
\hline Biofilm thickness ( $\mu \mathrm{m})$ & & 33 & 27 \\
\hline
\end{tabular}

*For all parameters average values are given

${ }^{\dagger}$ Retention time is defined as reactor liquid volume divided by effluent flow rate 


\section{Mathematical modeling}

Mathematical modeling was used to evaluate mechanisms of competition between autotrophic and heterotrophic biomass within the biofilm and in the bulk phase of the biofilm reactor. Three particulate fractions were considered. The autotrophic biomass $\left(\mathrm{X}_{\mathrm{A}}\right)$ is a combination of AOB and NOB. Organic substrate for the growth of the heterotrophic biomass $\left(\mathrm{X}_{\mathrm{H}}\right)$ was derived solely from soluble microbial products (SMP) produced during autotrophic growth. Inert particulate matter $\left(\mathrm{X}_{\mathrm{I}}\right)$ was the result of inactivation of $\mathrm{X}_{\mathrm{A}}$ and $\mathrm{X}_{\mathrm{H}}$. Substrate utilization associated production of SMPs was modeled for autotrophic growth where $\mathrm{f}_{\mathrm{UAP}, \mathrm{A}}\left(\mathrm{g}_{\mathrm{COD}, \mathrm{SMP}} / \mathrm{g}_{\mathrm{COD}, \text { biomass }}\right.$ ) is the stoichiometric parameter linking the rate of SMP production to the growth of $\mathrm{X}_{\mathrm{A}}$. A one-dimensional biofilm structure was assumed with mass transport of soluble substrates (oxygen, ammonium, SMP) by diffusion and mass transport of particulate matter $\left(\mathrm{X}_{\mathrm{A}}, \mathrm{X}_{\mathrm{H}}, \mathrm{X}_{\mathrm{I}}\right)$ by advection as a result of volume expansion due to growth. The rate of surface detachment was adjusted to result in different biofilm thicknesses. Detached biomass remained active and was suspended in the completely mixed bulk water. Basic model parameters were taken from Wanner and Reichert (1996). Simulations were performed using AQUASIM (Wanner and Morgenroth, 2004). All simulations were performed with a constant ammonia loading rate of $1.3 \mathrm{~g}_{\mathrm{N}} / \mathrm{d}$, and result in similar conditions as in the experimental part of this study.

\section{Results and discussion}

\section{Microbial community characterization}

All AOB detected in this study belonged to beta-subclass Proteobacteria, of which at least two distinct populations were present in both reactors. One of these populations was closely related to the model organism Nitrosomonas europaea, while the other population showed no close relationship with any recognized ammonia-oxidizers. Nitrite oxidation was performed in both reactors exclusively by Nitrospira-like bacteria. Nitrifying populations detected by the different probes were quantified and compared on the basis of their cellular area. These analyses revealed that in both reactors R1 and R2 NOB (probe Ntspa662) made up about 50\% of the total bacteria (EUB338 probe set). For AOB (probe Nso1225), however, the relative abundance was considerably smaller in R2 (long retention time) biofilm samples (23\%) than in R1 (short retention time, 53\%). Thus, while in reactor R1 nearly $100 \%$ of the total bacteria could be identified as either AOB or NOB, this rate was only $73 \%$ in reactor $\mathrm{R} 2$. The missing $27 \%$ are probably heterotrophic bacteria that grew on soluble microbial products (SMP) excreted by nitrifiers in the biofilm (Furumai and Rittmann, 1994). Experimental results of spatial distribution of nitrifiers in the biofilm (Figure 1) demonstrate that the nitrifying populations are uniformly distributed in reactor $\mathrm{R} 2$ biofilm. The $\mathrm{AOB}$ in reactor $\mathrm{R} 1$ displayed a small decrease in relative abundance towards the interior of the biofilm. These experimental results suggest that concentration gradients for soluble substrates into these relatively thin biofilms must not have been of significance.

\section{Simulation results compared with FISH analyses}

Experimental results showed that the reactor operated with a larger HRT (at the same ammonium loading rate) had a larger heterotrophic biomass fraction. The purpose of the mathematical modeling was to evaluate: (a) under what conditions $\mathrm{X}_{\mathrm{H}}$ can grow in the biofilm system; and (b) under what conditions $\mathrm{X}_{\mathrm{H}}$ will mainly grow in suspension rather than in the biofilm.

The amount of SMP produced due to autotrophic growth will determine the growth potential for heterotrophic biomass in the system. In Figure 2, the amount and location of heterotrophic biomass in the system is shown as a function of $f_{\mathrm{UAP}, \mathrm{A}}$ and HRT. It can be 


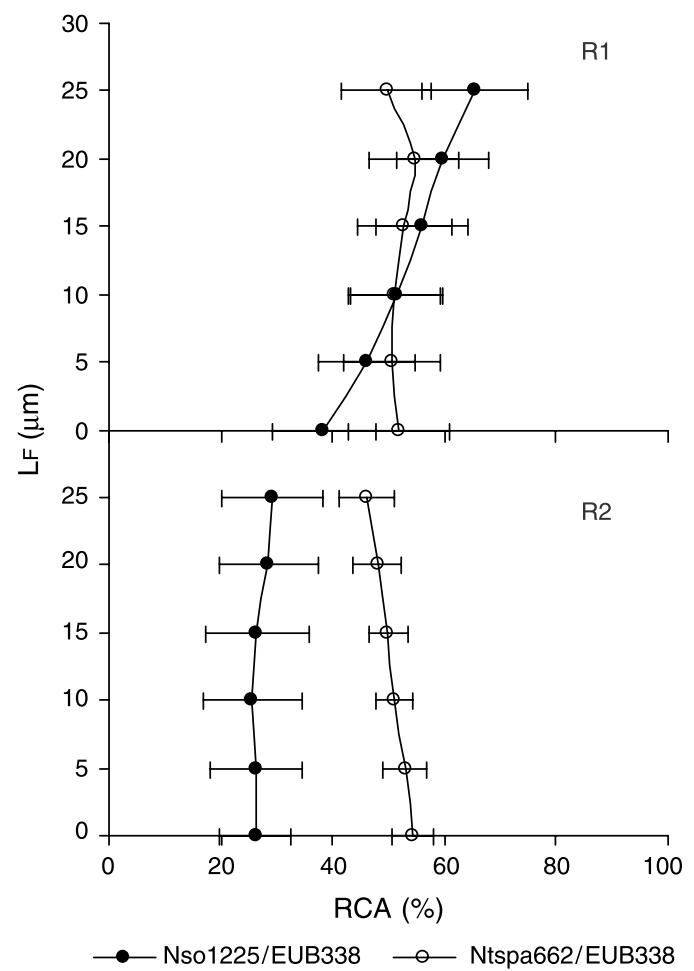

Figure 1 Averaged profiles of nitrifying bacteria over the thickness of the biofilm where RCA is the relative cellular area and $L_{F}$ is the distance from the substratum. Data points are the average $\pm 95 \%$ confidence interval

seen that there is a lower limit for $\mathrm{f}_{\mathrm{UAP}, \mathrm{A}}$ below which SMP production is insufficient to support heterotrophic growth. For lower HRTs, SMPs are washed out of the reactor faster and the total amount of ammonia converted decreases (data not shown). Comparing the different HRTs in Figure 2 shows that this minimum $\mathrm{f}_{\mathrm{UAP}, \mathrm{A}}$ required to support heterotrophic growth increases for decreasing HRTs. For example for $f_{U A P, A}=0.2 g_{C O D} / g_{C O D}$ the heterotrophic biomass is negligible for a HRT of $0.0175 \mathrm{~d}$ while there is a significant amount of $\mathrm{X}_{\mathrm{H}}$ for larger HRTs. Thus, a reduced availability of SMP in R1 could potentially explain the observed experimental results with a larger fraction of $\mathrm{X}_{\mathrm{H}}$ in $\mathrm{R} 2$. However, mechanisms and kinetics of SMP production are not well understood and values for $\mathrm{f}_{\mathrm{UAP}, \mathrm{A}}$ in the literature vary between 0.25 (Furumai and Rittmann, 1992) and $1.56 \mathrm{~g}_{\mathrm{COD}} /$ $\mathrm{g}_{\mathrm{COD}}$ (Lu et al., 2001). The extent of SMP production (i.e., $\mathrm{f}_{\mathrm{UAP}, \mathrm{A}}$ ) is strongly correlated

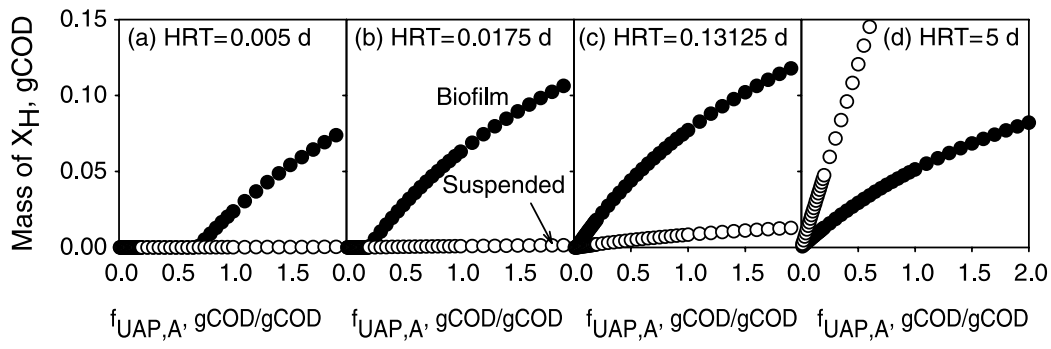

Figure 2 Amount of $X_{H}$ in the biofilm ( $)$ and suspended in the bulk phase $(O)$ as a function of SMP production due to autotrophic growth $\left(f_{U A P, A}\right)$ for different hydraulic retention times. HRTs used in the experimental part of this study were $0.0175 d(R 1)$ and $0.131 d(R 2)$ (simulations for a biofilm thickness of 
with the amount of $\mathrm{X}_{\mathrm{H}}$ in the system (Figure 2); however, the relationship between concentration of SMP in the effluent and the amount of $\mathrm{X}_{\mathrm{H}}$ is very weak (data not shown). For the case of HRT $=0.0175 \mathrm{~d}$ the concentration of SMP in the effluent increased only from $1.3 \mathrm{mg}_{\mathrm{COD}} / 1$ to $1.4 \mathrm{mg}_{\mathrm{COD}} / 1$ for $\mathrm{f}_{\mathrm{UAP}, \mathrm{A}}$ increasing from $0.2 \mathrm{~g}_{\mathrm{COD}} / \mathrm{g}_{\mathrm{COD}}$ to $2 \mathrm{~g}_{\mathrm{COD}} /$ $\mathrm{g}_{\mathrm{COD}}$ - the majority of SMP produced inside the biofilm are directly used up and never reach the bulk phase. Thus, for actual biofilm systems it will be difficult to predict the existence of heterotrophic growth based on bulk phase measurements of the organic substrate.

In Figure 3(a) the amount of $\mathrm{X}_{\mathrm{H}}$ in the biofilm and in suspension are shown as a function of HRT for different biofilm thicknesses. It can be seen that the majority of $\mathrm{X}_{\mathrm{H}}$ was located in the biofilm for HRTs smaller than $1 \mathrm{~d}$. For increasing HRTs the rate of washout from the bulk phase decreases resulting in a corresponding increase of $\mathrm{X}_{\mathrm{H}}$ growing in suspension and suspended $\mathrm{X}_{\mathrm{H}}$ dominate the system for HRTs larger than $10 \mathrm{~d}$. Van Benthum et al. (1997) had evaluated the location of $\mathrm{X}_{\mathrm{H}}$ in a similar biofilm airlift suspension reactor and had observed that heterotrophic biofilms were mainly found for HRTs smaller than the reciprocal max growth rate of heterotrophic biomass. The HRT of $10 \mathrm{~d}$ where the transition between growth in the biofilm and in suspension occurred in our simulations is significantly larger than the reciprocal of the maximum specific growth rate of $\mathrm{X}_{\mathrm{H}}(=0.22 \mathrm{~d})$. At HRTs between $1 \mathrm{~d}$ and $10 \mathrm{~d}$ heterotrophic biomass in the biofilm and in suspension coexist. For very low HRTs $(<0.001 \mathrm{~d})$ the total amount of $\mathrm{X}_{\mathrm{H}}$ decreases in the system. Suspended $\mathrm{X}_{\mathrm{H}}$ are reduced due to increased rates of washout with decreasing HRTs. Decreased HRTs also result in an increased washout of SMP that are produced in the system. Modeling results show that the extent and location of $\mathrm{X}_{\mathrm{H}}$ in the system are dependent on the HRT. In Figure 3(b) the mass of $\mathrm{X}_{\mathrm{A}}$ in the biofilm and suspended in the bulk phase are shown. It can be seen that the mass of $\mathrm{X}_{\mathrm{A}}$ in the biofilm is virtually independent of HRT for HRTs smaller than the reciprocal of the net maximum growth rate. For larger HRTs the amount of $\mathrm{X}_{\mathrm{A}}$ growing in the bulk phase increases.

Biomass and substrate concentrations within the biofilm are shown in Figure 4. To illustrate a potential layering of biomass the case of a thick biofilm with a significant SMP production was simulated. Autotrophic biomass dominates at the surface of the biofilm while the concentrations of $\mathrm{X}_{\mathrm{H}}$ increase towards the base of the biofilm. Such a biomass distribution is different from what has been reported in the literature (Wanner and Reichert, 1996; van Benthum et al., 1997) where heterotrophic biomass was expected to
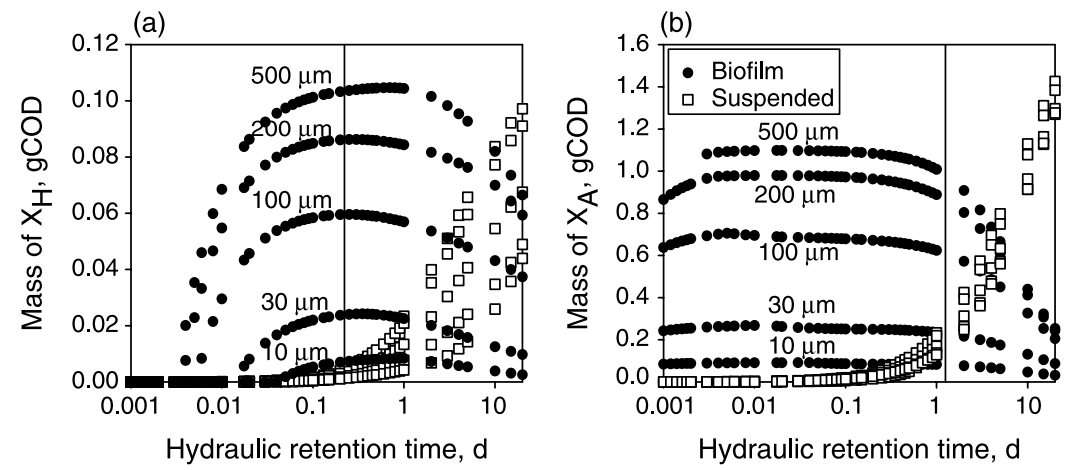

Figure 3 The amount of heterotrophic biomass (a) and autotrophic biomass (b) in the biofilm ( $)$ and suspended in the bulk phase (O) as a function of the HRT and biofilm thickness. The vertical line corresponds to the reciprocal maximum net growth rate where washout of suspended biomass would be expected for a completely mixed reactor without a biofilm (simulations with $\mathrm{fUAP}_{\mathrm{A}, \mathrm{A}}=0.25 \mathrm{gCOD}_{\mathrm{gCOD}}$ ) 

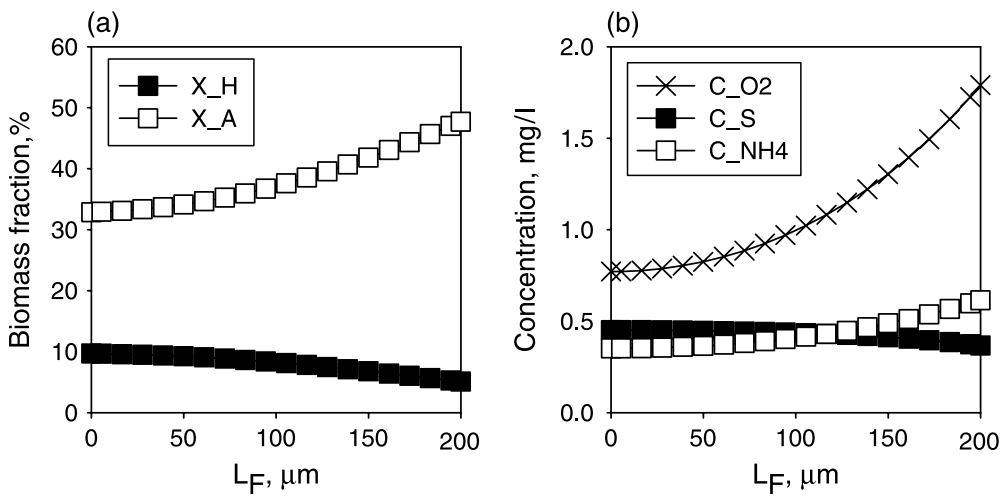

Figure 4 Biomass and substrate profiles over the thickness of the biofilm where $L_{F}$ is the distance from the substratum (simulations for a biofilm thickness of $200 \mu \mathrm{m}, \mathrm{HRT}=0.001 \mathrm{~d}, \mathrm{f}_{\mathrm{UAP}, \mathrm{A}}=1.56 \mathrm{gCOD} / \mathrm{gCOD}_{\mathrm{CO}}$ )

grow predominantly towards the surface of the biofilm. The difference in layering of $\mathrm{X}_{\mathrm{A}}$ and $\mathrm{X}_{\mathrm{H}}$ can be explained by the low growth rates of $\mathrm{X}_{\mathrm{H}}$ that are limited by SMP production. Substrate concentrations are shown in Figure 4(b). The concentrations of SMP increase towards the base of the biofilm as SMP are being produced within the biofilm resulting in a flux of SMP towards the surface of the biofilm and into the bulk water.

\section{Conclusions}

In the reactor operated with short retention time, about $100 \%$ of the biofilm consisted of nitrifiers, as compared to only $73 \%$ in the long retention time reactor.

At low HRTs, less SMP are available for heterotrophic growth resulting in purely autotrophic biofilms. This model prediction is consistent with the experimental observations.

At HRTs that are about an order of magnitude larger than the reciprocal of the net maximum growth rate the majority of the active biomass will grow suspended in the bulk phase rather than in the biofilm.

\section{Acknowledgements}

This research was in part supported by a CAREER award to EM from the National Science Foundation under grant No. BES-0134104.

\section{References}

American Public Health Association (1995). Standard Methods for the Examination of Water and Wastewater, 19th edn, American Public Health Association, Washington DC.

Daims, H., Nielsen, J.L., Nielsen, P.H., Schleifer, K.-H. and Wagner, M. (2001). In situ characterization of Nitrospira-like bacteria in wastewater treatment plants. Appl. Environ. Microbiol., 67, 5273-5284.

Furumai, H. and Rittmann, B.E. (1992). Advanced modeling of mixed populations of heterotrophs and nitrifiers considering the formation of soluble microbial products. Wat. Sci. Tech., 26(3-4), 493-502.

Furumai, H. and Rittmann, B.E. (1994). Interpretation of bacterial activities in nitrification filters by a biofilm model considering the kinetics of soluble microbial products. Wat. Sci. Tech., 30(11), 147-156.

Juretschko, S., Timmermann, G., Schmid, M., Schleifer, K.-H., Pommerening-Röser, A., Koops, H.-P. and

Wagner, M. (1998). Combined molecular and conventional analyses of nitrifying bacterium in activated sludge: Nitrosococcus mobilis and Nitrospira-like bacteria as dominant populations. Appl. Environ. Microbiol., 64, 3042-3051.

Kindaichi, T., Ito, T. and Okabe, S. (2004). Ecophysiological interaction between nitrifying bacteria and heterotrophic bacteria in autotrophic nitrifying biofilms as determined by microautoradiography- 
Lu, S.G., Imai, T., Ukita, M., Sekine, M., Higuchi, T. and Fukagawa, M. (2001). A model for membrane bioreactor process based on the concept of formation and degradation of soluble microbial products. Wat. Res., 35, 2038-2048.

Manz, W., Amann, R., Ludwig, W., Wagner, M. and Schleifer, K.-H. (1992). Phylogenetic oligonucleotide probes for the major subclasses of Proteobacteria: problems and solutions. Sys. Appl. Microbiol., 15, $593-600$.

Mobarry, B.K., Wagner, M., Urbain, V., Rittmann, B.E. and Stahl, D.A. (1996). Phylogenetic probes for analysing abundance and spatial organization of nitrifying bacteria. Appl. Environ. Microbiol., 62, 2156-2162.

Nogueira, R., Melo, L.F., Purkhold, U. and Wagner, M. (2002). Nitrifying and heterotrophic population dynamics in biofilm reactors: effects of hydraulic retention time and the presence of organic carbon. Wat. Res., 36, 469-481.

Rittmann, B.E., Regan, J.M. and Stahl, D.A. (1994). Nitrification as a source of soluble organic substrate in biological treatment. Wat. Sci. Tech., 30, 1-8.

van Benthum, W.A.J., van Loosdrecht, M.C.M. and Heijnen, J.J. (1997). Control of heterotrophic layer formation on nitrifying biofilms in a biofilm airlift suspension reactor. Biotechnol. Bioeng., 53(4), $397-405$

Wagner, M., Rath, G., Amann, R., Koops, H.-P. and Schleifer, K.-H. (1995). In situ identification of ammonia-oxidizing bacteria. Sys. Appl. Microbiol., 18, 251-264.

Wagner, M., Rath, G., Koops, H.-P., Flood, J. and Amann, R. (1996). In situ analysis of nitrifying bacteria in sewage treatment plants. Wat. Sci. Tech., 34, 237-244.

Wanner, O. and Morgenroth, E. (2004). Biofilm modeling with AQUASIM. Wat. Sci. Tech., 49(11-12), $137-144$.

Wanner, O. and Reichert, P. (1996). Mathematical-modeling of mixed-culture biofilms. Biotechnol. Bioeng., 49(2), 172-184. 